\title{
Genistein reduces angiogenesis and apoptosis in women with endometrial hyperplasia
}

\author{
This article was published in the following Dove Press journal: \\ Botanics: Targets and Therapy \\ 27 January 2015 \\ Number of times this article has been viewed
}

\author{
Roberta Granese ${ }^{1, *}$ \\ Alessandra Bitto ${ }^{2, *}$ \\ Francesca Polito ${ }^{2}$ \\ Onofrio Triolo' \\ Domenico Giordano' \\ Angelo Santamaria' \\ Francesco Squadrito ${ }^{2}$ \\ Rosario D'Anna' \\ 'Department of Paediatric, \\ Gynaecological, Microbiological, \\ and Biomedical Sciences, ${ }^{2}$ Department \\ of Clinical and Experimental Medicine, \\ Section of Pharmacology, University \\ of Messina, Messina, Italy \\ *These authors contributed equally to \\ this work
}

Correspondence: Alessandra Bitto Department of Clinical and Experimental Medicine, Section of Pharmacology, University of Messina, Torre Biologica 5th Floor, Via C Valeria,

Messina 98I 25, Italy

Email abitto@unime.it
Abstract: Endometrial hyperplasia without cytological atypia is commonly treated with progestins, but other treatments may be available with equivalent efficacy and reduced side effects. Here, we evaluate the effect of genistein aglycone on angiogenesis and apoptosis-related markers women with endometrial hyperplasia. Premenopausals $(n=38)$ with nonatypical endometrial hyperplasia were administered either genistein aglycone $(54 \mathrm{mg} / \mathrm{day}, \mathrm{n}=19)$ or norethisterone acetate $(10 \mathrm{mg} /$ day, $\mathrm{n}=19)$ on days $16-25$ of the menstrual cycle and evaluated for 6 months. Biopsies were taken during hysteroscopy at baseline and 6 months, and symptoms including excessive uterine bleeding were assessed at baseline and 3 and 6 months following recruitment. The expression of angiogenesis (Vegf), epithelial ( $E g f$ and $T g f b$ ), and apoptosis-related (Bax, $B c l-2$, and Casp-9) molecules, were assessed in uterine biopsies at baseline and after 6 months of therapy. Follicle-stimulating hormone, luteinizing hormone, estradiol, SHBG, and progesterone levels were also measured. After 6 months, $42 \%$ of genistein aglycone-administered patients had a significant improvement of symptoms compared to $47 \%$ of norethisterone acetate subjects. No significant differences were noted in hormone levels for any treatment. Gene expression revealed a significant reduction in Vegf, $E g f$, and $T g f b(P<0.05$ versus baseline), and an increase in proapoptotic molecules (Bax and Casp-9), with a concomitant decrease in $B c l-2$ values $(P<0.05)$ in both groups. These results suggest that genistein aglycone might be useful for the management of endometrial hyperplasia without atypia in women who cannot or do not wish to be treated with progestin.

Keywords: genistein, endometrial hyperplasia, Vegf, Bcl-2, Bax, Casp-9

\section{Introduction}

Endometrial hyperplasia is defined as a glandular proliferation that results in an increase in the ratio of glands to stroma, and is most common in the premenopausal period. In about $12 \%$ of women during this time, ${ }^{1}$ chronically high levels of estrogen, not offset by adequate progesterone production (anovulation) may be responsible for endometrial tissue hyperplasias and the often-correlated symptoms of menometrorrhagia. Under these circumstances, the endometrium initially loses the capacity for secretory maturation, and subsequently, with the persistence of the estrogenic stimulus, can assume a morphology very similar to endometrial cancer. ${ }^{2}$

Chronic exaggerated estrogenic stimulation may induce synthesis of its estrogen receptors (ERs) and also of progesterone receptors, ${ }^{3}$ which are thus present at high levels in the hyperplastic endometrium. ${ }^{4}$ Moreover, estradiol $\left(\mathrm{E}_{2}\right)$ induces the synthesis of different mitogenic factors, including VEGF and its receptor ${ }^{5,6}$ and EGF, which are promoters of endometrial proliferation. ${ }^{3,5}$ In addition, a significant correlation 
between steroid-receptor expression and TGF $\beta$ expression has also been demonstrated. ${ }^{5}$ TGF $\beta$ acts as a cell-growth inhibitor, ${ }^{7}$ and ER $\alpha$ inhibits TGF $\beta$ signaling via a nongenomic mechanism. ${ }^{7}$

In a recent study, ${ }^{8}$ we tested the therapeutic action of the isoflavone genistein on endometrial hyperplasia. Genistein in fact has a weak effect in stimulating the growth of the endometrium when administered in menopause, but in an environment rich in estrogen, it acts as an antiestrogen. ${ }^{9,10}$ Genistein binds the ER, either as an agonist or antagonist, ${ }^{11}$ acting as a selective ER modulator, with full agonistic activity on the $\alpha$-receptor and partial agonistic on the $\beta$-receptor, but with a greater affinity on the latter. In that study, we showed that genistein and estrogens compete for ER binding, ${ }^{9,12}$ with a resultant significant decline in receptor expression. In addition, genistein administration has antiestrogenic activity, decreasing the expression of $\alpha$-receptors, mainly present in the uterus, ${ }^{10}$ which results in regression of hyperplasia comparable to that seen with treatment with progestins.

In this study, we evaluated the gene expression of the known growth factors (Vegf, Egf, and $T g f b$ ) and of some the key molecules that regulate apoptosis (Bax, Casp-9, and $B c l-2)$ which might be involved in the development of hyperplasia in premenopausal women. The aim of the study was to understand if the positive effects of genistein on endometrial hyperplasia are at least in part mediated through apoptotic and growth-related pathways.

\section{Subjects and methods}

Between January and November 2010, 38 consecutive premenopausal women with abnormal uterine bleeding and diagnosed with nonatypical endometrial hyperplasia were enrolled in this observational study. All procedures were approved by the Ethics Committee of Messina University Hospital (approved December 2009, 47/09), and the protocol followed the principles of the Declaration of Helsinki. All study participants gave their written informed consent. All subjects wrote informed consent, and underwent diagnostic hysteroscopy during the endometrial proliferative phase of their menstrual cycle (cycle days 8-10). Hysteroscopy was performed without anesthesia using a hysteroscope of $3 \mathrm{~mm}$ and one of $1.9 \mathrm{~mm}$ (Karl Storz, Germany) and with an optical angle of $30^{\circ}$. The uterine cavity was distended with a solution of $0.9 \%$ potassium chloride.

Characterization of the endometrium on hysteroscopic examination followed the criteria reported by Baggish et al. ${ }^{13}$ The appearance of the endometrium under direct vision was described as "normal" if compatible with the proliferative phase, "normal with small hyperplastic areas" if only small areas of thickness were present, and "hyperplastic" if the entire endometrium was thick. All subjects underwent endometrial biopsy for histological examination to confirm the visual observation and to exclude any possible malignancy.

Subjects were counseled by an expert gynecologist, and based on their own choice, received either genistein $54 \mathrm{mg}$ daily ( $\mathrm{n}=19$; Genivis; Mastelli, Italy) or norethisterone acetate $10 \mathrm{mg}$ /day on cycle days 16-25 $(\mathrm{n}=19)$. Subjects were treated for 6 months, or until the regression of hyperplasia (Figure 1).

Baseline data collection included age, parity, menstrual history, weight, height, body mass index, waist and hip size, and qualitative description of the amount of uterine bleeding. Baseline laboratory measurements included follicle-stimulating hormone $(\mathrm{FSH})$, luteinizing hormone $(\mathrm{LH}), \mathrm{E}_{2}$, progesterone, and SHBG. During hysteroscopy, a biopsy sample was taken for pathology assessment and a small piece separately stored at $-20^{\circ} \mathrm{C}$ for determination of messenger RNA (mRNA) expression of Vegf, Egf, Tgfb, Bax, Casp-9, and Bcl-2.

$\mathrm{E}_{2}, \mathrm{FSH}, \mathrm{LH}, \mathrm{SHBG}$, and progesterone were routinely evaluated as previously described. ${ }^{8}$ Symptomatic and pathological descriptions followed previously published criteria. $^{8}$

After 3 and 6 months, all women were asked for symptoms and changes in uterine bleeding, and an ultrasound evaluation of endometrial thickness was performed. After 6 months, all baseline data points were again measured,

For the gene-expression study, the extraction of total mRNA was performed from endometrial biopsies under sterile conditions using Trizol (Invitrogen, Italy) following the manufacturer's protocol and evaluated by quantitative real-time polymerase chain reaction (PCR). For each sample, $5 \mathrm{mg}$ of mRNA was reverse-transcribed into complementary deoxyribonucleic acid (cDNA) and $3 \mathrm{~mL}$ of cDNA was amplified in duplicate using the TaqMan Universal PCR Master Mix containing primer and TaqMan validated probes designed to specifically target human Vegf, Egf, Tgfb, Bax, Casp-9, and Bcl-2 (all reagents from Applied Biosystems, USA). For the reaction, we used an SDS 7300 Real Time PCR instrument (Applied Biosystems). The result was expressed as number of copies of the target gene compared to the housekeeping gene $(A c t b)$, and the $2^{-\Delta \Delta \mathrm{Ct}}$ mean values of both groups were compared with those of an arbitrary calibrator.

Statistical analysis was performed with SPSS 11 (SPSS, USA). To compare data between groups, Student's $t$-test 


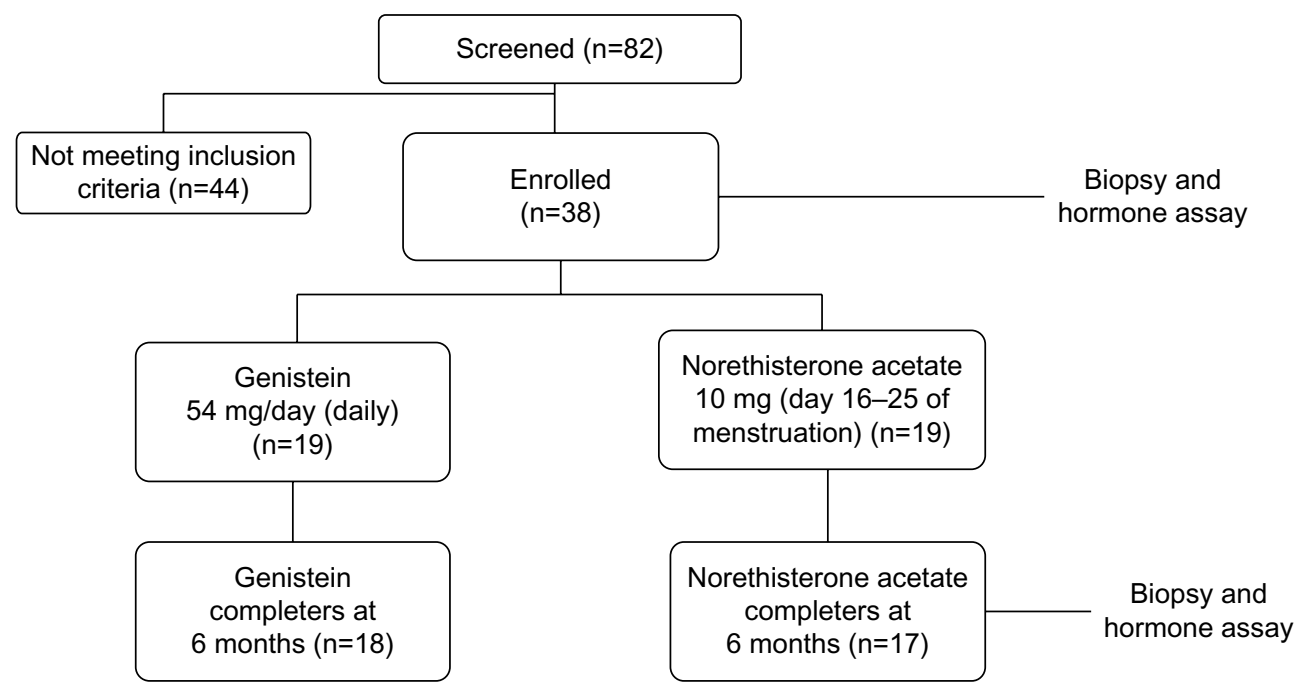

Figure I Study flowchart.

was used for parametric data, and the Mann-Whitney $U$-test for nonparametric data. The significance of difference was assessed for parametric data by a two-way repeated-measures analysis of variance, followed by post hoc analyses where indicated. Dichotomous variables were analyzed with the $\chi^{2}$ test and the Fisher's exact test, when appropriate. A $P$-value $<0.05$ was considered statistically significant.

\section{Results}

The two study groups (Figure 1) showed similar characteristics regarding age (genistein, 47.2 \pm 3.1 years; norethisterone acetate, $47.2 \pm 3.4$ years), body mass index (genistein, $24 \pm 1.1$; norethisterone acetate, $23.5 \pm 1.5$ ), parity (genistein, 1.3 \pm 1.2 ; norethisterone acetate, 1.2 \pm 1.1 ), and endometrial thickness evaluated at days 8-10 of the menstrual cycle (genistein, $7 \pm 3 \mathrm{~mm}$; norethisterone acetate, $7 \pm 2.6 \mathrm{~mm}$ ). After 3 months, ten genistein subjects had significant improvement in bleeding, seven had moderate improvement, and two subjects had persistent symptoms.

In the norethisterone acetate-treated group, nine subjects had significant improvement in bleeding, five had moderate improvement, and four subjects had persistent symptoms. During this study period, one subject was withdrawn because she started antihypertensive therapy.

At the second follow-up, the abnormal bleeding in eleven genistein-administered subjects was completely absent (further confirmed by histology in nine women), reduced in four, and persistent in three. In the norethisterone acetate-treated group, clinical improvement was reported in eleven subjects and a mild improvement in two, while four subjects showed persistent clinical symptoms. Histological examination of biopsies confirmed regression of hyperplasia in the eleven women from both groups, and its persistence in the remaining subjects. Two women with persistent bleeding, one in each group, decided to undergo to surgical ablation. A nonparametric test showed a significant decrease $(P<0.05)$ of symptoms in both genistein and norethisterone acetate groups compared to baseline after 6 months.

After 6 months of therapy, levels of $\mathrm{E}_{2}, \mathrm{FSH}, \mathrm{LH}$, and SHBG were assayed. No significant differences were found for responders or nonresponders (data not shown). It is noteworthy that $\mathrm{E}_{2}$ levels remained elevated in all nonresponders, while a tendency for decreased $\mathrm{E}_{2}$ was observed for genistein-responsive subjects (baseline, $79.94 \pm 49.47 \mathrm{pg} / \mathrm{mL}$; 6 months, $64.27 \pm 23.69 \mathrm{pg} / \mathrm{mL}$; not significant). In the norethisterone acetate group, 14 subjects reported water retention, and none in the genistein group.

Regarding the expression of the genes studied in the endometrial tissue, we found that $\operatorname{Veg} f$ was significantly reduced after 6 months of treatment in the genistein-treated group $(P<0.01)$ and in the norethisterone acetate-treated group $(P<0.01)$ compared to basal expression levels (Figure 2A). The reduction observed in the genistein group was significantly more pronounced than that observed in the norethisterone acetate-treated group $(P<0.05)$. Expression of $E g f$ was also significantly reduced in the two study groups after 6 months of treatment $(P<0.005$, Figure 2B). Moreover, in the two groups, even gene expression of $T g f b$ decreased significantly after 6 months $(P<0.005$, Figure 2C). Angiogenic, growth-related, and apoptotic molecule gene expression showed a significant change after 6 months. In particular, a significantly enhanced expression of the proapoptotic 

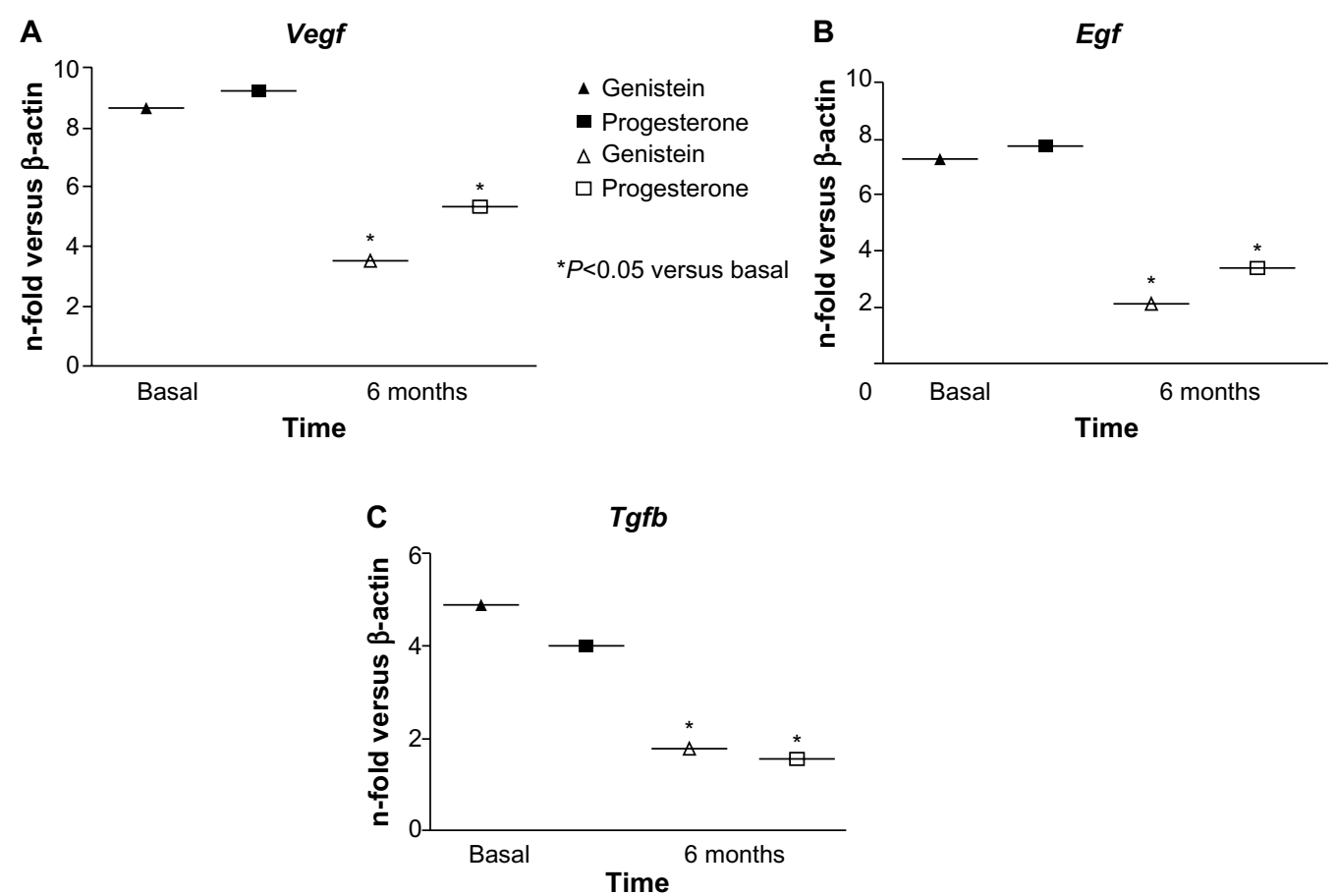

Figure 2 Gene expression of (A) Vegf, (B) Egf, and (C) Tgfb at baseline and after 6 months, expressed as $n$-fold of $\beta$-actin. Data are expressed as median values.

molecules Casp-9 and Bax (Figure 3A and C, respectively) was noted after 6 months of treatment in both treatment groups $(P<0.05$ for both). Finally, a concomitant decrease in the expression of $B c l-2$ was observed after 6 months in both study groups $(P<0.05$, Figure $3 \mathrm{~B})$.

\section{Discussion}

The data presented here demonstrate a modulating action of genistein on the apoptotic and growth-related pathways in the hyperplastic endometrium. Clinical efficacy was essentially identical in the genistein- and progesterone-treated groups,

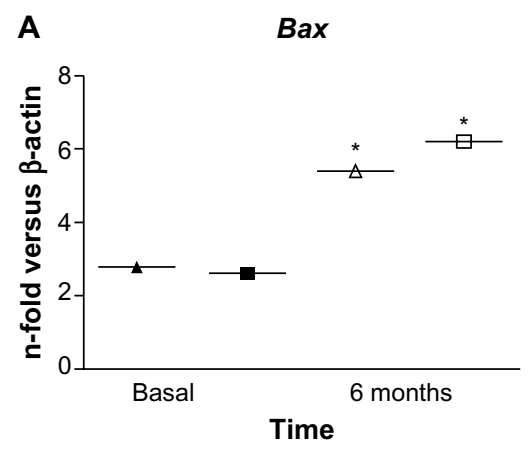

B

Bcl-2

Genistein

- Progesterone

$\Delta$ Genistein

$\square$ Progesterone

${ }^{\star} P<0.05$ versus basal
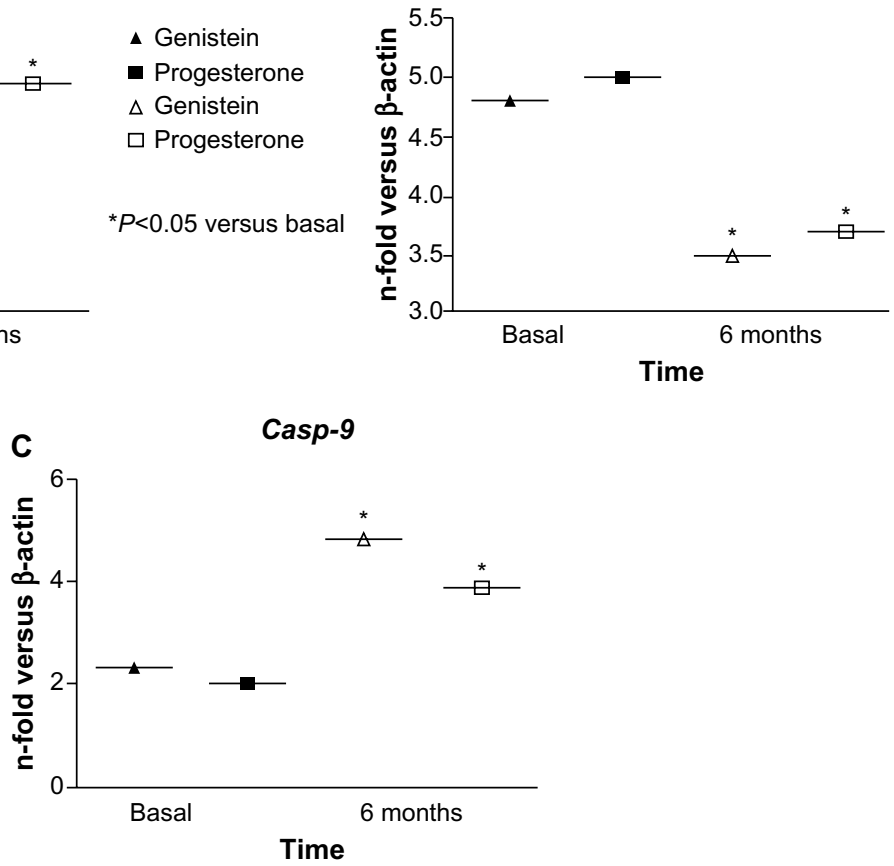

Figure 3 Gene expression of (A) Bax, (B) Bcl-2, and (C) Casp-9 at baseline and after 6 months, expressed as n-fold of $\beta$-actin. Data are expressed as median values. 
while the genistein group demonstrated a more favorable adverse-event profile.

In the presence of a hyperestrogenic environment in premenopausal women, with endometrial hyperplasia genistein showed a significant reduction in hyperplasia and related symptoms, ${ }^{8}$ compatible with the antiestrogenic effects of genistein that have previously been shown in vitro. ${ }^{14}$ It is known that more than $80 \%$ of hyperplasia cases without atypia and more than $50 \%$ of cases of complex hyperplasia with atypia spontaneously regress. ${ }^{15,16}$ For this reason, we further studied some of the possible molecular pathways involved in the mechanism of action of genistein aglycone in promoting the reduction of endometrial hyperplasia in subjects without signs of atypia. Growth factors involved in the establishment of endometrial hyperplasia act through kinase-associated receptors, and stimulate tissue and vascular growth. In this study, we demonstrated the inhibitory effect of

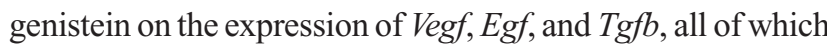
are regulated by estrogens in the endometrium. ${ }^{17,18}$ Therefore, genistein acted in two different ways - reducing the cascade of kinase activation that follows growth-factor binding, and inhibiting the production of the mRNA for these growth factors - acting through ER $\beta$, which is a known inhibitor of proliferation at the transcriptional level. We hypothesize that elevated estrogen levels promote enhanced ER activation, which is responsible for the activation of proliferative genes and the downregulation of antiproliferative genes. Therefore, pro/antiapoptotic homeostasis is altered in favor of cell survival and proliferation. Since deregulation of proliferation and apoptosis is known to contribute to neoplastic transformation and growth, maintaining the homeostasis of BAX, $\mathrm{Bcl}-2$, and caspase 9 expression is of importance to avoid the onset of atypia in the hyperplastic endometrium. Genistein, by interfering with estrogen binding and receptor expression, is indirectly able to induce apoptosis and stop endometrial proliferation, as suggested by the observed increase in Casp- 9 and Bax gene expression and $B c l-2$ reduction.

The strengths of this paper are the well-defined population sample, the high adherence to the study protocol, and the demonstration of genistein's molecular mechanism of action in this well-defined condition. A potential limitation of this report is the small sample of subjects observed and the lack of follow-up information after the end of treatment. However, our data are supported by solid demonstration of genistein's mechanism of action, somewhat similar to progestin, but with a stronger safety profile. ${ }^{19-21}$

The effects of genistein were studied on the same pathways that are known to be affected by progesterone-receptor activation, which have already been observed in different subsets by other authors, and our data are in agreement with their results. ${ }^{15}$

\section{Conclusion}

The present study provides support for the possible use of genistein as an alternative therapy for those women that prefer to use a natural approach for the treatment of endometrial hyperplasia or those who have experienced undesirable side effects with progesterone therapy.

\section{Acknowledgments}

The authors are thankful to Dr Robert Levy, MD, for English-language editing. This research was supported by departmental funding.

\section{Author contributions}

All authors contributed toward data analysis, drafting and revising the paper and agree to be accountable for all aspects of the work.

\section{Disclosure}

The authors report no conflicts of interest in this work.

\section{References}

1. Brun JL, Belaisch J, Rivel J, Hocké C. [Endometrial hyperplasias resistant to progestins: alternatives to traditional treatments]. Gynecol Obstet Fertil. 2002;30:244-251. French.

2. Munro MG. Classification of menstrual bleeding disorders. Rev Endocr Metab Disord. 2012;13:225-234.

3. Baird DT, Bramley TA, Hawkins TA, Lumsden MA, West CP. Effect of treatment with LHRH analogue Zoladex on binding of oestradiol, progesterone and epidermal growth factor to uterine fibromyomata. Horm Res. 1989;32 Suppl 1:154-156.

4. Karlsson B, Granberg S, Wikland M, et al. Transvaginal ultrasonography of the endometrium in women with postmenopausal bleeding - a Nordic multicenter study. Am J Obstet Gynecol. 1995;172:1488-1494.

5. Kim MR, Park DW, Lee JH, et al. Progesterone-dependent release of transforming growth factor-betal from epithelial cells enhances the endometrial decidualization by turning on the Smad signalling in stromal cells. Mol Hum Reprod. 2005;11:801-808.

6. Sağsöz H, Saruhan BG. The expression of vascular endothelial growth factor and its receptors (flt1/fms, flk1/KDR, flt4) and vascular endothelial growth inhibitor in the bovine uterus during the sexual cycle and their correlation with serum sex steroids. Theriogenology. 2011;75: 1720-1734.

7. Ito I, Hanyu A, Wayama M, et al. Estrogen inhibits transforming growth factor beta signaling by promoting Smad2/3 degradation. J Biol Chem. 2010;285:14747-14755.

8. Bitto A, Granese R, Triolo O, et al. Genistein aglycone: a new therapeutic approach to reduce endometrial hyperplasia. Phytomedicine. 2010;17: 844-850.

9. Kayisli UA, Aksu CA, Berkkanoglu M, Arici A. Estrogenicity of isoflavones on human endometrial stromal and glandular cells. J Clin Endocrinol Metab. 2002;87:5539-5544.

10. Taylor AH, Al-Azzawi F. Immunolocalisation of oestrogen receptor beta in human tissues. J Mol Endocrinol. 2000;24:145-155. 
11. Anderson JB, Anthony M, Messina M, Garner SC. Effects of phytoestrogens on tissues. Nutr Res Rev. 1999;12:75-116.

12. Mylonas I, Jeschke U, Makovitzky J, et al. Immunohistochemical expression of steroid receptors and glycodelin A in isolated proliferative human endometrial glandular cells after stimulation with tamoxifen and phytoestrogens (genistein and daidzein). Anticancer Res. 2003;23: 1119-1125.

13. Baggish MS, Barbot J, Valle RF. Diagnostic and Operative Hysteroscopy: A Text and Atlas. 2nd ed. Chicago: Year Book Medical; 1989.

14. Sampey BP, Lewis TD, Barbier CS, Makowski L, Kaufman DG. Genistein effects on stromal cells determines epithelial proliferation in endometrial co-cultures. Exp Mol Pathol. 2011;90:257-263.

15. Rattanachaiyanont $M$, Angsuwathana $S$, Techatrisak K, Tanmahasamut $P$, Indhavivadhana S, Leerasiri P. Clinical and pathological responses of progestin therapy for non-atypical endometrial hyperplasia: a prospective study. J Obstet Gynaecol Res. 2005;31:98-106.

16. Kurman RJ, Kaminski PF, Norris HJ. The behavior of endometrial hyperplasia. A long-term study of "untreated" hyperplasia in 170 patients. Cancer. 1985;56:403-412.
17. Xuebing P, TinChiu L, Enlan X, Jing L, Xiaowu H. Is endometrial polyp formation associated with increased expression of vascular endothelial growth factor and transforming growth factor-31? Eur J Obstet Gynecol Reprod Biol. 2011;159:198-203.

18. Wada-Hiraike $\mathrm{O}$, Hiraike $\mathrm{H}$, Okinaga $\mathrm{H}$, et al. Role of estrogen receptor beta in uterine stroma and epithelium: insights from estrogen receptor beta-/- mice. Proc Natl Acad Sci U S A. 2006;103:18350-18355.

19. Bitto A, Polito F, Atteritano M, et al. Genistein aglycone does not affect thyroid function: results from a three-year, randomized, double-blind, placebo-controlled trial. J Clin Endocrinol Metab. 2010;95:3067-3072.

20. Marini H, Bitto A, Altavilla D, et al. Breast safety and efficacy of genistein aglycone for postmenopausal bone loss: a follow-up study. J Clin Endocrinol Metab. 2008;93:4787-4796.

21. D'Anna R, Cannata ML, Marini H, et al. Effects of the phytoestrogen genistein on hot flushes, endometrium, and vaginal epithelium in postmenopausal women: a 2-year randomized, double-blind, placebocontrolled study. Menopause. 2009;16:301-306.
Botanics: Targets and Therapy

\section{Publish your work in this journal}

Botanics: Targets and Therapy is an international, peer-reviewed, open access journal focusing on the discovery and development of active compounds based upon or found naturally occurring in the plant kingdom that may have therapeutic potential in any disease state. The manuscript management system is completely online and includes a very

\section{Dovepress}

quick and fair peer-review system. Visit http://www.dovepress.com/ testimonials.php to read real quotes from published authors. 